\title{
Height at diagnosis of insulin dependent diabetes in patients and their non-diabetic family members
}

\author{
THOMAS J SONGER, RONALD E LAPORTE, NAOKO TAJIMA, TREVOR J ORCHARD, \\ BRUCE S RABIN, MARK S EBERHARDT, JANICE S DORMAN, KAREN J CRUICKSHANKS, \\ DRUIE E CAVENDER， DOROTHY J BECKER， ALLAN L DRASH
}

\begin{abstract}
Height at the onset of insulin dependent diabetes mellitus was evaluated in 200 newly diagnosed children, 187 non-diabetic siblings, and 169 parents. Diabetic children 5-9 years of age at diagnosis were consistently taller than the national average. Non-diabetic siblings of the same age were also tall. Diabetic children aged 14 or over at diagnosis were short, while their siblings and parents were of normal height. Diabetic children positive for islet cell antibodies were taller than those without islet cell antibodies. No association between height and HLA
\end{abstract}

Department of Epidemiology, Graduate School of Public Health, University of Pittsburgh, Pittsburgh, Pennsylvania PA 15261, USA

THOMAS J SONGER, BS

RONALD E LAPORTE, PHD, associate professor

NAOKO TAJIMA, MD, visiting assistant professor

TREVOR J ORCHARD, MB, MMEDSCI, associate professor

JANICE S DORMAN, PHD, instructor

KAREN J CRUICKSHANKS, BA

Department of Pathology, School of Medicine, University of Pittsburgh, Pittsburgh, Pennsylvania

BRUCE S RABIN, MD, professor

Technology and Operational Research Branch, Division of Diabetes Control, Center for Prevention Services, Centers for Disease Control, Atlanta, Georgia

MARK S EBERHARDT, PHD, epidemiologist

Department of Internal Medicine, University of Texas, Health Science Center at Dallas, Dallas, Texas

DRUIE E CAVENDER, PHD, assistant professor

Division of Endocrinology and Metabolism, Department of Pediatrics, School of Medicine, University of Pittsburgh and Children's Hospital of Pittsburgh, Pittsburgh, Pennsylvania

DOROTHY J BECKER, MB, FCP(PAED), associate professor

ALLAN L DRASH, MD, professor

Correspondence and requests for reprints to: $\mathrm{T} J$ Songer. antigens was found. Non-diabetic siblings at high risk for the disease were closer in height to the diabetic children than were the lower risk, non-diabetic siblings. Siblings, particularly those under 10, were also significantly more obese than the general population.

Deviations in growth in patients with insulin dependent diabetes mellitus appear to be related to age at diagnosis and a factor(s) not related to parental height.

\section{Introduction}

There has been considerable interest in evaluating the growth of children who have insulin dependent diabetes mellitus. Most research has been concerned with height at the time of diagnosis of the disease and subsequent growth changes in the years after diagnosis. ${ }^{1.8}$ Research assessing height at the time of diagnosis may also be of particular importance for understanding the pathogenesis of diabetes. Studies evaluating height at diagnosis have shown that children developing diabetes are tall at diagnosis, ${ }^{4-10}$ of normal height, or short. ${ }^{2311}$ Height at diagnosis is important because growth changes are not rapid. Thus differences in height at diagnosis may indicate a long prediabetic stage, perhaps lasting years, rather than a rapid onset of diabetes. A long prediabetic stage is consistent with current theories of the aetiology of insulin dependent diabetes mellitus. ${ }^{213}$

Additionally, some studies have suggested that certain factors related to changes in growth before the diagnosis of diabetes may be directly related to the aetiology of insulin dependent disease. Mirakian et al and Hoskins et al have proposed respectively that immunological ${ }^{13}$ and metabolic ${ }^{11}$ factors are likely to be associated with the alterations in growth during the prediabetic phase. Though genetic factors have an important role in growth, there is little information on the potential associations of genetic factors and height in newly identified cases of insulin dependent diabetes mellitus. We have therefore evaluated the determinants of height at diagnosis in a large cohort of children with newly diagnosed insulin dependent diabetes mellitus. 


\section{Subjects and methods}

Patients-Height was determined at presentation of insulin dependent diabetes mellitus in 200 patients consecutively diagnosed at the Children's Hospital of Pittsburgh from February 1979 to August 1982. All were aged under 18 at diagnosis and were discharged from the hospital taking insulin. Presenting characteristics and genetic and immunological data were collected on all patients utilising serum samples (collected on the day of diagnosis) and a standardised chart review procedure ${ }^{14}$ HLA tissue typing for A, B, and DR antigens was performed by standard techniques. ${ }^{1415}$ Krell and Rabin's method was employed to detect islet cell antibodies. ${ }^{1617} \mathrm{C}$ Peptide was measured by radioimmunoassay using a Novo Laboratories kit. Survey data were obtained from the parents within one week of diagnosis to determine the family history of diabetes in first degree relatives. A family history of autoimmune or immune disease was subsequently collected. The height recorded at diagnosis or at a clinic visit within six weeks of diagnosis was used to determine relative height from standardised growth charts ${ }^{1814}$ and expressed as percentile ranking. The 200 patients represented $70 \%$ of all newly diagnosed patients with insulin dependent diabetes mellitus in Allegheny County, Pa, during the period of case ascertainment. The demographic characteristics of the 200 patients at presentation (table I) were similar to those of subjects aged under 18 in our population based county registry of insulin dependent diabetes mellitus. ${ }^{25}$ Hence the children diagnosed at the children's hospital during $1979-82$ were probably representative of newly diagnosed patients.

TABLE I-Demographic characteristics of patients, siblings, and parents

\begin{tabular}{lcll}
\hline & Patients & Siblings & Parents \\
\hline Sample size & 200 & 187 & 169 \\
Mean age in years at diagnosis (SD) & $8 \cdot 4(4 \cdot 1)$ & & \\
Mean age in years at height measurement (SD) & $8 \cdot 4(4 \cdot 1)$ & $12 \cdot 7(5 \cdot 6)$ & $36 \cdot 2(7 \cdot 3)$ \\
Sex (\% female) & $52 \cdot 0$ & $46 \cdot 0$ & $54 \cdot 0$ \\
Race (\% white) & $91 \cdot 5$ & $94 \cdot 2$ & $97 \cdot 0$ \\
\hline
\end{tabular}

First degree relatives-In order to assess the genetic component of height in the children with insulin dependent diabetes mellitus, first degree, nondiabetic relatives were also studied. Heights and weights were available from all siblings and parents tested for glucose tolerance. Relative height and body mass index (weight $(\mathrm{kg})$ divided by height $(\mathrm{m})^{2}$ ) were calculated for 187 nondiabetic siblings ( $57 \%$ of the total siblings aged over 3 ) and 169 parents ( $42 \%$ of parents). ${ }^{18-20}$ Mid-parental relative height was also calculated for 71 pairs of available parents. HLA-A and B haplotypes and data on islet cell antibodies were available for all siblings.

High risk siblings-Non-diabetic siblings were considered at high risk of developing insulin dependent diabetes mellitus if they were (a) HLA identical for the $A$ and $B$ antigens with their brother or sister with the disease $(n=36),(b)$ positive for islet cell antibodies $(n=6)$, or $(c)$ converters to insulin dependent diabetes mellitus $(n=2)$. Forty siblings were so identified. ${ }^{1221}$ Four were included in more than one analysis because they were either islet cell positive and HLA identical $(n=3)$ or HLA identical and converted to insulin dependent diabetes mellitus $(n=1)$.

Statistical analysis-A one sample $t$ test was employed to compare the relative height and body mass index of the parents, siblings, and patients with the 50 th percentile values for the United States population. ${ }^{18-20} \mathrm{~A}$ two sample $t$ test compared siblings with patients. When more than two groups were compared analysis of variance was used with analysis of covariance controlling for age at diagnosis. Independent determinants of relative heigh at diagnosis in the patients were evaluated by stepwise multiple regression.

\section{Results}

\section{OVERALL RELATIVE HEIGHT}

Table II shows the relative heights in each age group of diabetic patients and their non-diabetic siblings. The patients diagnosed in the youngest age group (0-4 years; $\mathbf{n}=36)$ did not differ significantly from the national average. Data on siblings under 4 years of age were not available for comparison because only children over 3 were eligible for glucose tolerance tests.

Patients with insulin dependent diabetes mellitus diagnosed between 5 and 9 years of age $(n=68)$ and siblings aged 5-9 years $(n=47)$ were significantly taller than the national average (mean (SD) relative height percentiles: patients $64(29), \mathrm{p}<0.001$; siblings $57(25), \mathrm{p}<0.05)$. In this age group $17(24 \%)$ of the patients and $\operatorname{six}(13 \%)$ of the siblings were over the
90 th percentile of national height. Interestingly, no significant differences in height were found between the patients and the siblings. At the time of the growth acceleration phase and puberty (ages 10-13) the heights of both the patients $(n=65)$ and siblings $(n=47)$ approximated to the 50 th percentile of national height. At ages 14-17 years the patients with onset of diabetes $(\mathrm{n}=22)$ were significantly shorter than the national average (mean relative height percentile $38(30) ; p<0.05)$. The siblings $(n=43)$, however, were of normal height (relative height percentile $54(26)$ ). The final, mean adule

TABLE II-Relative heights in each age group of patients with insulin dependent diabetes mellitus and non-diabetic siblings

\begin{tabular}{lccccc}
\hline & \multicolumn{4}{c}{ Age (years) } \\
\cline { 2 - 5 } & $0-4$ & $5-9$ & $10-13$ & $14-17$ \\
\hline $\begin{array}{l}\text { Relative height percentiles: } \\
\text { Patients with diabetes }\end{array}$ & 47 & 64 & 50 & 38 \\
Non-diabetic siblings & $\star$ & 57 & 44 & 54 \\
\hline
\end{tabular}

^Data not available (see text).

heights (18 years and over) of the older siblings $(n=36$; relative heigh percentile 48 ) and the parents (relative height percentile 51) were virtuall identical with the United States national average. No differences in heigh@o with sex were found in patients, parents, or siblings. Parental height was also evaluated by the age group of the respective patients and siblings to see if tallness in the younger children was related to tallness in the parents. ThE्छ mid-parental relative heights in each age group did not differ significantly from the national average, so that the increased growth in the prepubertat patients and siblings could not be explained by associations with parenta height.

RELATIVE HEIGHT AND IMMUNOLOGICAL VARIABLES, GENETIC VARIABLES, AND RESIDUAL $\beta$ CELL FUNCTION

Children with islet cell antibodies detected at the time of diagnosis of diabetes $(n=94)$ were significantly taller than the diabetic children withou these antibodies $(\mathrm{n}=41)$ (relative height percentiles $60 v 41 ; \mathrm{p}<0.001)$. Thio relation of islet cell antibodies and relative height appeared in the pre pubertal age group (0-9 years: relative height percentiles $63(n=63) v 4 \bar{్}$ $(n=13) ; p=0.05)$ and approached significance in the pubertal-postpubertab̆ age group (10-17 years: relative height percentiles $53(n=31) v 40(n=28) \mathbb{Q}$ $\mathrm{p}=0 \cdot 07$ ). By contrast, the few siblings positive for islet cell antibodies $(\mathrm{n}=6$ ) were not significantly different in height from the siblings negative fos antibodies $(\mathrm{n}=116)$ (relative height percentiles $45 v 49)$.

Analysis of relative height by HLA-DR antigens showed no difference in height by HLA-DR state (mean relative height percentiles: $\mathrm{DR} 3 / \mathrm{X}=53$ $\mathrm{DR} 4 / \mathrm{X}=54 ; \mathrm{DR} 3 / 4=55 ; \mathrm{DRX} / \mathrm{X}=49$ ). Siblings and parents also did no show any relation between relative height and the HLA-A or B antigens Relative height was not associated with a family history of autoimmune disease or a family history of insulin dependent diabetes. Similarly, relative height was not related to the residual $\beta$ cell function of the patients at diagnosis of diabetes, as measured by serum $C$ peptide values.

The independent determinants of relative height at diagnosis in the patients were evaluated with a stepwise multiple regression model. The variables of age, race, sex, mid-parental relative height, presence of islen cell antibodies, history of recent infection, and history of insulin dependen diabetes mellitus in first degree relatives were selected. From these the onl fo significant independent determinants of height for the patient at onset were mid-parental height and islet cell antibody positivity. This indicates that if addition to the expected contribution of parental height, the presence of isleț cell antibodies was also significantly associated with height in the patients. $\sigma$

\section{RELATIVE HEIGHT IN HIGH RISK SIBLINGS}

Table III gives the relative height percentiles of siblings at high risk of developing insulin dependent diabetes mellitus. The height patterns of the high risk, non-diabetic siblings appeared to be closer to those of theip? diabetic siblings than to those of their non-diabetic brothers or sisters. High risk siblings aged under $10(n=12)$ were taller than the national averageo (mean (SD) relative height percentile $65(25) ; \mathrm{p}<0.05)$, and high risk siblings aged 10-17 $(n=17)$ were somewhat shorter than the national average (mean relative height percentile $39(28) ; \mathrm{p}=0 \cdot 10)$. High risk siblings aged 10-17 also tended to be shorter than low risk siblings $(n=73)$ (mean relative⿳亠二口 
height percentiles $39 v 52 ; \mathbf{p}=0 \cdot 08$ ), while high risk siblings aged $0-9$ years were not significantly different in height from low risk siblings in this age group $(n=50)$. At ages 18-30 the high risk siblings $(n=11)$ also exhibited height patterns similar to those of the low risk siblings $(n=25)$.

Table IV shows the relation between relative height and the sharing state of HLA haplotypes in all siblings. Within each HLA sharing group the relative height of the patients was correlated with the relative height of the siblings. Non-diabetic siblings who were HLA identical with their respective diabetic brother or sister were much closer in height to the diabetic patient than were siblings who were not HLA identical. The population ${ }^{1820}$ and used to measure the relative weight of these subjects, controlling for height because no standardised charts exist for body mass index in the general population. In this analysis the prepubertal male (mean relative body mass index percentile $92 ; \mathrm{p}<0.01)$ and prepubertal female non-diabetic siblings (mean relative body mass index percentile $85 ; \mathrm{p}<0.005$ ) were consistently more obese than the United States norms (table V). After age 10 only the female siblings had body mass indexes significantly greater than the 50th percentile (mean relative body mass index percentile: ages 10$17=67, p<0 \cdot 05 ;$ ages $18-24=86 ; p<0 \cdot 025$. The high prevalence of obesity was evidenced by finding that overall $44(23 \%)$ of the siblings had body mass

TABLE III-Relative height of high risk siblings by risk factors for developing insulin dependent diabetes mellitus

\begin{tabular}{|c|c|c|c|c|}
\hline & \multicolumn{4}{|c|}{ Overall relative height percentiles } \\
\hline & All ages & Ages 0-9 & Ages 10-17 & Ages $18-30$ \\
\hline \multirow{3}{*}{$\begin{array}{l}\text { Siblings HLA identical } \\
\text { Siblings positive for islet cell antibodies } \\
\text { Sibling converters to insulin dependent diabetes } \\
\text { mellitus }\end{array}$} & $49(n=36)$ & $67(n=10)$ & $40(n=16)$ & $44(n=10)$ \\
\hline & $45(n=6)$ & $56(n=2)$ & $24(n=2)$ & $55(\mathrm{n}=2)$ \\
\hline & $21(n=2)$ & & $21(n=2)$ & \\
\hline Total means & $49(n=40)$ & $65(\mathrm{n}=12)$ & $39(n=17)$ & $48(n=11)$ \\
\hline
\end{tabular}

TABLE IV—Correlations of relative height by HLA haplotype sharing

\begin{tabular}{lccc}
\hline & $\begin{array}{c}\text { Correlation } \\
\text { coefficient }\end{array}$ & Significance & $\begin{array}{c}\text { No of } \\
\text { observations }\end{array}$ \\
\hline $\begin{array}{l}\text { Patient's relative height and sibling's } \\
\text { relative height: }\end{array}$ & & & \\
$\quad \begin{array}{l}\text { Sibling HLA share 2 } \\
\text { Sibling HLA share 1 }\end{array}$ & $\mathrm{r}=0.72$ & $\mathrm{p}<0.001$ & 36 \\
$\begin{array}{l}\text { Sibling HLA share 0 } \\
\text { Patient's relative height and random }\end{array}$ & $\mathrm{r}=0.30$ & $\mathrm{p}<0.05$ & $\mathbf{N}$ \\
sibling's relative height: & & & 36 \\
$\quad \begin{array}{l}\text { Sibling HLA share 2 } \\
\text { Sibling HLA share 1 }\end{array}$ & $\mathrm{r}=0.74$ & $\mathrm{p}<0.01$ & 32 \\
Sibling HLA share 0 & $\mathrm{r}=0.35$ & $\mathrm{p}<0.05$ & 48 \\
& $\mathrm{r}=0.37$ & $\mathrm{p}<0.05$ & 29 \\
\hline
\end{tabular}

TABLE $\mathrm{v}-$ Relative body mass index values for siblings of diabetic children and their parents

\begin{tabular}{|c|c|c|c|c|}
\hline \multirow{2}{*}{$\begin{array}{l}\text { Age } \\
\text { group } \\
\text { (years) }\end{array}$} & \multicolumn{2}{|c|}{ Male } & \multicolumn{2}{|c|}{ Female } \\
\hline & Siblings & Parents & Siblings & Parents \\
\hline $\begin{array}{c}0-9 \\
10-17 \\
18-24 \\
25-34 \\
35-44 \\
45-54 \\
55-64\end{array}$ & $\begin{array}{l}92(p<0.01 ; n \\
46(N S ; n=49 \\
82(N S ; n=15\end{array}$ & $\begin{array}{l}61(N S ; n=36) \\
68(N S ; n=28) \\
76(N S ; n=13)\end{array}$ & $\begin{array}{l}85(p<0.01 ; n \\
67(p<0.05 ; n \\
86(p<0.02 ; n \\
80(N S ; n=3)\end{array}$ & $\begin{array}{l}76(p<0 \cdot 02 ; n=41) \\
45(N S ; n=35) \\
75(N S ; n=13)\end{array}$ \\
\hline
\end{tabular}

correlation between relative height in patients with insulin dependent diabetes mellitus and relative height in siblings sharing two HLA antigens was significantly greater $(p=0.003)$ than the correlation between relative height in diabetic patients and relative height in siblings sharing one HLA antigen. Similar associations were found when a random sibling from each family was selected. The analysis including the random sibling was conducted because in the initial analyses larger families contributed more data points than smaller families. A random sibling was selected in each family to eliminate this potential bias. The patterns of results, however, were the same for the two analyses.

\section{BODY MASS INDEX}

The differing degrees of weight loss that occur in insulin dependent diabetes mellitus before diagnosis prevent any clear assessment of a patient's actual weight from measurements made at diagnosis. Body mass indexes of non-diabetic siblings and parents, however, offer important insights into the possible role of obesity in these families. Relative body mass index was estimated from the heights and weights of the non-diabetic family members in this study and the heights and weights of the general United States indexes above the 90th percentile for obesity. Mothers aged 25-34 (mean relative body mass index percentile $76 ; p<0.025$ ) had body mass indexes significantly greater than the 50 th percentile. Fathers were in the normal range.

Since height is correlated with body mass index in children, standardised weight for height charts ${ }^{18}$ were also used as a measure of relative weight in prepubertal siblings to control for potential influences of increased height on body mass index. No normative weight for height charts exist for pubertal or postpubertal children. The pattern of results, however, was similar to that for body mass index. Prepubertal boys $(n=36)$ weighed significantly more than the national average for their heights (mean (SD) percentile for relative weight for height $62(29) ; p<0 \cdot 01)$. Prepubertal girls $(n=26)$ were also larger than the national average (mean percentile $57(24)$ ), though not significantly so.

\section{Discussion}

This study shows that children aged 5-9 years at the diagnosis of insulin dependent diabetes and their similarly aged siblings were taller than expected. Patients diagnosed after puberty were shorter 
than the national average, but non-diabetic siblings were of average height. Jefferson et al have recently reported a similar age specific relation with height; their prepubertal patients with insulin dependent diabetes mellitus were also of normal height at 0-4 years and taller than the national average at 5-9 years."2 These results may explain the discordant findings in published work because previous studies have not evaluated age specific relations.

Relative height in high risk siblings was much closer to that in patients with insulin dependent diabetes mellitus than was the relative height in low risk siblings. This suggests that the processes that alter height in the patients may be more prevalent in the nondiabetic, high risk siblings than in their lower risk brothers and sisters.

Our results are clear evidence of important alterations in growth in diabetic children and their siblings. Moreover, the differences in growth seen in the prepubertal patients and siblings and the postpubertal patients did not appear to be related to the genetic influence of parental height. In the older diabetic children the reduced height may have been the result of an extended prediabetic phase of low availability of insulin, as suggested by Hoskins et al."

The accelerated growth in the younger patients and non-diabetic siblings was particularly interesting. One possibility suggested by this investigation is that accelerated growth may be the result of an autoimmune phenomenon. Both the increased height as well as the development of insulin dependent diabetes mellitus may be related to autoimmune abnormalities. In the evaluation the presence of islet cell antibodies was associated with increased height, particularly in the prepubertal patients. Our results, however, do not fully support the autoimmune hypothesis, since there was no association of height with DR3/X (the HLA antigen thought to be associated with autoimmune disease). Also, there was no relation of height to a family history of autoimmune disease or a family history of insulin dependent diabetes mellitus.

As an alternative hypothesis, obesity at a young age may be a determinant of both accelerated growth and the development of insulin dependent diabetes mellitus. Previous research has shown that obesity is biologically related to height in children, obese children having accelerated growth and an earlier puberty. ${ }^{23}$ Also, children destined to develop insulin dependent diabetes mellitus may weigh more than those who do not go on to develop the disease. ${ }^{2+}$ The role of obesity could not be evaluated in our diabetic patients because of the variable degrees of weight loss associated with diabetes before diagnosis. In the evaluation of non-diabetic family members there was evidence of an increased prevalence of obesity in first degree relatives. The results suggest that obesity may cluster in families with insulin dependent diabetic children. This relation of weight to height, however, needs to be confirmed in larger samples of non-diabetic siblings.

Our results show distinct differences in height which are strongly associated with age at onset. Moreover, prepubertal patients with insulin dependent diabetes mellitus and their prepubertal, nondiabetic siblings had a common familial acceleration of growth that was not related to parental height. A factor unrelated to parental height seems to be mediating the growth patterns of these children. Autoimmunity or familial obesity, or both, may help explain the increased height of children diagnosed before 10 years of age. 3 Alterations in height, therefore, may be directly related to the aetiology of insulin dependent diabetes mellitus.

We thank Dr Rose Fritsch for her thoughtful comments. Research was supported by grant AM24021 and the Renziehausen Fund.

\section{References}

1 Wiske PS, Wentworth SM, Norton JA Jr, Epstein S, Johnston CC Jr. Evaluation of bone mass an growth in young diabetics. Metabolism 1982;31:848-54.

Court S, Parkin M Roberts. DF, Wentzel J. HLA antigensand growth in diabetic children $\overline{\bar{\omega}}$ Hum Biol 1982;9:329-36.

3 Jivani SKM, Ravner PHW. Does control influence the growth of diabetic children? Arch Dis Child $1973 \cdot 48 \cdot 109-15$

4 Edelsten AD, Hughes IA, Oakes S, Gordon IRS, Savage DCL. Height and skeletal maturity in children with newly-diagnosed juvenile-onset diabetes. Arch Dis Child 1981;56:40-4.

5 Boyd JD, Nelson MV. Growth studies of children with diabetes mellitus. Am $\mathcal{J}$ Dis Child 1928;35:753-61.

6 Craig JO. Growth as a measurement of control in the management of diabetic children. Postgrad Med F 1970;46:607-10

7 Hielt K, Braendholt V, Kamper J, Vestermark S. Growth in children with diabetes mellitus. Dan Med Bull 1983;30:28-33

8 Ladd WS, Day CS. Growth in children with diabetes mellitus. Am f Dis Child 1926;32:812-38. I 9 Drayer NM. Height of diabetic children at onset of symptoms. Arch Dis Child 1974;49:616-20. N 10 Pond H. Some aspects of growth in diabetic children. Postgrad Med f 1970;46:616-23.

11 Hoskins PJ, Leslie RDG, Pyke DA. Height at diagnosis of diabetes in children: a study in identicak twins. Br Med $\mathcal{F}$ 1985;290:278-80.

12 Srikanta S, Ganda OP, Rabizadeh A, Soeldner JS, Eisenbarth GS. First degree relatives of patients with type I diabetes mellitus. Islet-cell antibodies and abnormal insulin secretion. $N$ Engl f Med $\vec{\nexists}$ 1985;313:461-4

13 Mirakian R, Botazzo GF, Cudorth AG, Richardson CA, Doniach D. Autoimmunity toanterio pituitary cells and the pathogenesis of insulin-dependent diabetes mellitus. Lancet 1982;i:755-8. 음 pituitary cells and the pathogenesis of insulin-dependent diabetes mellitus. Lancet 1982;1:755-8.을 terard MS, Wagener DK, Orchard TJ, el al. HLA heterogeneity of insulin-depend

15 National Institute of Allergy and Infectious Diseases, National Institutes of Health. Manual of tissue typing techniques. Bethesda, Md: NIAID, NIH, 1979-80:39.

16 Krell J, Rabin BS. Comparison of an immunohistochemical and immunofluorescence procedure to detect antibody to pancreatic islet cells. Diabetes 1984;33:709-11.

7 Cavender D, Rabin B, Finegold D. A new, sensitive immunohistochemical assay for islet celle cytoplasmic antibodies [Abstract]. Diabetes 1984;33(suppl 1):63A

18 Hamill PVV, Drizd TA, Johnson CL, Reed RB, Roche AF, Moore WM. Physical growth: National Center for Health Statistics percentiles. Am 7 Clin Nutr 1979;32:607-29.

19 National Center for Health Statistics. NCHS growth curves for children (birth-18 years). Ser 11. NoO 165. Washington, DC. Department of Health, Education, and Welfare, 1978. (DHEW publication No ( PHS) 78-1650.

20 National Center for Health Statistics. Weight and height of adults 18-74 years of age: United States, 1971-74. Ser 11. No 211. Washington, DC: Department of Health, Education, and Welfare, 1979. DHEW . Ner 11 . Washington, DC: Dep

21 Cavender DE, Wagener DK, Rabin BS. The Pittsburgh insulin-dependent diabetes mellitus study: HLA antigens and haplotypes as risk factors for the development of IDDM in IDDM플 patients and their siblings. 7 Chronic Dis 1984:37:555-8 patients and their siber 5 Child 1985;60:1144-8.

23 Frisch RE, Revelle R. The height and weight of adolescent boys and girls at the time of peak velocity of growth in height and weight: longitudinal data. Hum Biol 1969;41:536-9.

24 Baum JD, Ounsted M, Smith MA. Weight gain in infancy and subsequent development of diabetes mellitus in childhood. Lancet 1975 ;ii: 866 .

25 LaPorte RE, Fishbein HA, Drash AL, et al. The Pittsburgh Insulin-dependent Diabetes Mellitus. (IDDM) Registry; the incidence of insulin-dependent diabetes mellitus in Allegheny County, Pennsylvania (1965-1976). Diabetes 1981;30:279-84.

(Accepted 25 March 1986)

\section{YEARS AGO}

That the public do not obtain that amount of protection from adulteration which, it was intended by Parliament, the Sale of Food Act of 1875 should confer, is becoming more and more apparent; nor is it to be expected that the terrors of the law will be heightened, and the temptation to unscrupulous traders lessened, by such decisions as those recently given by the magistrates at Stratford, when three persons, who had been summoned for selling as pure coffee mixtures containing from 45 to 65 per cent. of chicory, escaped the penalties which the law was intended to enforce, the Bench refusing to give any reason for their decision. That the practice of adulterating coffee, to even greater extent than this, is a practice but too common, has been shown by an analysis of forty-three samples of coffee and coffee-mixtures bought in London during March and April of this year, which is said to have yielded an average proportion of 50 per cent. of pure coffee; in one case, there was 93 per cent. of adulterants. Chicory, which costs the retailer about threepence per pound, continues to be one of the most common of the adulterants $\sigma$ employed, in some cases amounting to three-fourths of chicory to one-fourth of coffee. But other mixtures, of even cheaper kind, are sometimes used fore the purposes of adulteration, including burnt sugar, roast and ground roots of dandelion, carrots, parsnips, locust beans, lupines, and other seeds.? Hardly one case, we are told, of 500 of successful misrepresentation or fraud, is now brought to light or punished; and this we can readily believe. It is, indeed, high time that some more effective steps were taken to carry outo successfully the intentions of the Legislature, and to strengthen the hands of the inspectors under the Act in the endeavour to secure for the public pure and wholesome food, and a public accurate declaration of the contents of the many admixtures, now largely sold for the sole benefit of the trader, and too the gross injury and injustice of the consumer. (British Medical fournat 1886;ii:263.) 